\title{
Effect of Pre Emptive Administration of Meloxicam on Rumen Motility in Dystocia Affected Buffaloes
}

\author{
Umed Singh Mehra ${ }^{*}$, S. C. Arya ${ }^{2}$, Praveen Kadian ${ }^{1}$, Rajan Chaudhary ${ }^{1}$, \\ Ravi Dutt ${ }^{2}$, Rajendra Yadav ${ }^{3}$ and Pankaj Kumar ${ }^{4}$ \\ ${ }^{1}$ Department of Animal Husbandry and Dairying, Haryana, India \\ ${ }^{2}$ Department of Veterinary Gynaecology and Obstetrics, LUVAS, Hisar, \\ Haryana-125004, India \\ ${ }^{3}$ Regional Referral Veterinary Diagnostic and Extension Centre (RVDEC), \\ Mahendergarh, India \\ ${ }^{4}$ Assistant Disease Investigation Officer, Department of Veterinary Public Health and \\ Epidemiology, LUVAS, Hisar, Haryana-125004, India \\ *Corresponding author
}

\section{A B S T R A C T}

Keywords

Administration of Meloxicam, Rumen

Motility, Dystocia

Affected Buffaloes

Article Info

Accepted:

16 April 2018

Available Online:

10 May 2018
Number of analgesics of NSAID group viz., meloxicam and rofecoxib etc has been used in management of post-operative pain, ruminal motility was observed to be adversely affected by pre-emptive administration of meloxicam in dystocia affected buffaloes and caesarean operation further added to this effect on rumen function. The decreased ruminal motility may be due to stress of dystocia and associated anorexia. The buffaloes included in the present study had been anorectic for varying periods before the case was presented for treatment. Present study has been undertaken on the effect of meloxicam administration on ruminal motility in 41 cases of dystocia affected buffaloes.

\section{Introduction}

Dystocia is defined as delayed or difficult calving, sometimes requiring significant human assistance. It generally has a lower incidence in buffalo but still has a considerable impact on buffalo production (1$2 \%$ ). However, Khan et al analyzed the incidence of abnormal calvings in buffalo in various reports and found it to be between 5.6$12.6 \%$ in Murrah, $8.94 \%$ in Jaffarabadi and between 4.6 to $5.4 \%$ in Surti buffalo. The reasons for such a low incidence in buffalo could be due to anatomical differences between cattle and buffalo. Buffalo have a more capacious pelvis, larger area of ileum, a free and easily separable fifth sacral vertebra, easily dilatable small sized vaginal canal, and 
elongated and wide apart vulvar lips. These anatomical differences mean that the first and second stages of labor in the buffalo can easily be completed within 20-70 min. A large number of risk factors for dystocia have been identified.

Normal rumen motility as described by Schalk and Amadon (1928), and by Dukes (1955) originates in the reticulum by two rapid contractions of the walls of that oavity, the second immediately following the first. As a result of these contractions, liquid material is thrown into the rumen. Before the completion of the second reticular contraction, however, the anterior pillar of the rumen begins to contract, forming a barrier to the second reticular outflow. The wave of rumen contraction begun at the anterior pillar, proceeds posterially involving the entire dorsal part of the rumen, and, as these structures relax, the ventral sac goes into contraction. These forces ingest a forward and upward into the anterior dorsal region of the rumen. Following the primary wave, just mentioned, is a secondary wave similar to the primary, but whole involves only the rumen.

This study was undertaken to obtain further fundamental information on how rumination, rumen motility, and other physiological behaviours of Buffaloes are affected by Dystocia.

\section{Materials and Methods}

The present investigation was carried out on 41 dystocia affected buffaloes brought to the teaching veterinary clinics, CCS HAU, Hisar for treatment.

Before attempting to relieve the dystocia, a complete history of the case with regard to parity, stage of gestation, duration of problem and previous handling of the case by the field staff/laymen, was obtained from the owner.
The nature and cause of dystocia was determined on the basis of systemic examination and depending upon the cause of difficulty in birth and the duration and pervious handling of the case, obstetrical management was carried out. All the animals received routine supportive therapy consisting of parentral antibiotics, dexamethasone, fluid therapy, hemostatic, uterine stimulants and intrauterine antiseptics post-delivery of the foetus.

Grouping on the basis of obstetrical operation

Group I: comprised of 19 buffaloes in which foetus were removed by Caesarian section without administration of meloxicam prior to surgery.

Group II: was comprised of 22 caesarean operated buffaloes treated preemptively with meloxicam.

\section{Sub-grouping on the basis of obstetrical operation}

Group- $\mathrm{I}_{\mathrm{A}}$ consisted of 8 buffaloes in which dystocia were relieved by non-surgical techniques and without pre-emptive administration of meloxicam.

Group- $\mathrm{I}_{\mathrm{B}}$ comprised of 11 buffaloes in which foetus was removed by laparohysterotomy without administration of meloxicam prior to surgery.

Group $\mathrm{II}_{\mathrm{A}}$ included 8 meloxicam administered dystocia affected buffaloes treated non-surgically.

Group $\mathrm{II}_{\mathrm{B}} \quad$ was comprised of 14 caesarean operated buffaloes treated preemptively with meloxicam. 
Sub grouping on the basis of survival of dam following obstetrical management

Group S consisted of 24 buffaloes which survived following treatment.

Group D included 17 buffaloes which died during or after obstetrical operation.

Groups $S_{\text {I }}$ and $S_{\text {II }}$ consisted of 13 and 11 buffaloes respectively which survived without/with pre emptive administration of meloxicam.

Groups $D_{\text {I }}$ and $D_{\text {II }}$ were composed of six and 11 buffaloes respectively which died following obstetrical intervention without/with administration of meloxicam.

Groups $S_{B}$ and $D_{B}$ included 12 and 13 caesarean operated buffaloes respectively which survived or died following operation, Irrespective of treatment with Meloxicam.

\section{Rumen motility}

Rumen motility is a very important physiological function and should always be evaluated during illness. Learn to time rumen contractions and use this skill as a diagnostic tool when you have a Buffalo that seems ill.

A healthy Buffalo has rumen contractions (motility) from 1-3 times per minute. Motility frequency often depends on when the Buffalo last ate a mass of forage or hay. If the meal was recent, motility will be faster because the rumen is working at its peak to mix its contents. If the last food was a while ago, contractions will be fewer.

Place your fingertips on the Buffalo's left side, halfway between the ribs and hips, and about $1 / 4$ of the way down from the top line. This soft, hollow area high on either side below the loin is called the paralumbar fossa, and the literal translation is "the depression next to the lumbar vertebrae". You should feel a hard mass. This is the rumen contents. Leave your fingers pressed against it until you feel the rolling motion of a rumen contraction. Count the seconds (use a watch) until you feel the next one. With a stethoscope pressed firmly against the rumen, you can also hear contractions and the gurgling noises of rumen gas.

This may have noticed that when look at a Buffalo from the front or the rear that its right side bulges upward slightly more than the left side. That is because the intestines are under the rumen on the right side and lift it a little. The Buffalo's tummy looks fuller after eating, and it can be hard to tell whether or not it is bloated.

Total rumen motility (units) was evaluated based on several indexes such as contraction frequency for 5 minutes (f), contraction duration ( $\mathrm{t}$ ) and amplitude (a), the latter presented with the following formula from their average values:

$A=f x . t x . a x$

\section{Results and Discussion}

\section{Grouping on the basis of obstetrical operation}

Group-I: comprised of 19 buffaloes in which foetus were removed by Caesarian section without administration of meloxicam prior to surgery.

Group II: was comprised of 22 caesarean operated buffaloes treated pre-emptively with meloxicam.

\section{Sub-grouping on the basis of obstetrical operation}

Group $-\mathrm{I}_{\mathrm{A}}$ consisted of 8 buffaloes in which dystocia were relieved by non-surgical techniques and without pre-emptive administration of meloxicam. 
Group- $\mathrm{I}_{\mathrm{B}}$ comprised of 11 buffaloes in which foetus was removed by laparohysterotomy without administration of meloxicam prior to surgery.

Group $\mathrm{II}_{\mathrm{A}}$ included 8 meloxicam administered dystocia affected buffaloes treated nonsurgically.

Group $\mathrm{II}_{\mathrm{B}}$ was comprised of 14 caesarean operated buffaloes treated pre-emptively with meloxicam.

Sub grouping on the basis of survival of dam following obstetrical management

Group S consisted of 24 buffaloes which survived following treatment.

Group D included 17 buffaloes which died during or after obstetrical operation.

Groups $S_{\text {I }}$ and $S_{\text {II }}$ consisted of 13 and 11 buffaloes respectively which survived without/with pre emptive administration of meloxicam.

Groups $D_{\text {I }}$ and $D_{\text {II }}$ were composed of six and 11 buffaloes respectively which died following obstetrical intervention without/with administration of meloxicam.

Groups $\mathrm{S}_{\mathrm{B}}$ and $\mathrm{D}_{\mathrm{B}}$ included 12 and 13 caesarean operated buffaloes respectively which survived or died following operation, Irrespective of treatment with Meloxicam.

Pre-emptive administration of meloxicam had noticeable influence on rumen motility in dystocia affected buffaloes which has been shown in Table 1. Rumen motility was significantly $(\mathrm{p}<0.05)$ improved (increased) at 24 hours post treatment in buffaloes without pre-emptive administration of meloxicam $(0.737 \pm 0.129)$ when compared with 0 hour and 2 hour value $(0.450 \pm 0.114)$. The effect of meloxicam administration was more pronounced in non-surgically treated than the caesarean operated buffaloes.

Effect of obstetrical operation on rumen motility has been depicted in Table 2 . Caesarean operation was observed to have a compounding effect with meloxicam treatment on rumen motility in buffaloes suffering from dystocia.

Rumen motility was significantly $(\mathrm{p}<0.05)$ improved by 24 hours post treatment in the non-surgically treated buffaloes when compared with the surgically treated buffaloes not administered meloxicam.

However, this difference in rumen motility between surgically and non-surgically treated buffaloes was non-significant when meloxicam was administered prior to obstetrical intervention.

Marked difference was recorded in ruminal motility in buffaloes which survived when compared with those which died. Ruminal motility was observed to be significantly $(\mathrm{p}<0.01)$ improved by 24 hours post treatment in survivors $(0.875 \pm 0.091)$ in comparison to pre-treatment mean count of $0.333 \pm 0.098$ (Table 3). On the contrary the rumen motility decreased non-significantly in animals that died.

The mean rumen motility at 24 hours post treatment in this group was recorded as $0.133 \pm 0.090$ as compared to $0.352 \pm 0.119$ at the start of treatment.

However, among the caesarean operated buffaloes there was no significant difference in ruminal motility of animals which died or survived following surgery. 
Table.1 Effect of pre emptive administration of meloxicam on rumen motility in dystocia affected buffaloes

\begin{tabular}{|c|c|c|c|}
\hline \multirow[t]{2}{*}{ Group } & \multicolumn{3}{|c|}{ Sampling interval Rumen Motility } \\
\hline & 0 hour & 2 hours & 24 hours \\
\hline $\mathrm{I}(\mathrm{n}=19)$ & $0.211 \pm 0.096 \mathrm{a}$ & $0.211 \pm 0.096 \mathrm{a}$ & $0.737 \pm 0.129 b$ \\
\hline$I(n=22)$ & $0.455 \pm 0.109$ & $0.190 \pm 0.088$ & $0.450 \pm 0.114$ \\
\hline IA $(n=8)$ & $0.125 \pm 0.125 a$ & $0.125 \pm 0.125 a$ & $1.125 \pm 0.125 b$ \\
\hline IIA (n=8) & $0.375 \pm 0.183$ & $0.375 \pm 0.183$ & $0.714 \pm 0.184$ \\
\hline IB $(n=11)$ & $0.273 \pm 0.141$ & $0.273 \pm 0.141$ & $0.545 \pm 0.157$ \\
\hline IIB $(n=14)$ & $0.429 \pm 0.137$ & $0.077 \pm 0.077$ & $0.308 \pm 0.137$ \\
\hline
\end{tabular}

Table. 2 Effect of obstetrical operation on rumen motility in dystocia affected buffaloes

\begin{tabular}{|l|c|c|c|}
\hline \multirow{2}{*}{ Group } & \multicolumn{3}{|c|}{ Sampling interval Rumen Motility } \\
\hline I A $(\mathbf{n = 8})$ & $\mathbf{0}$ hour & 2 hours & 24 hours \\
\hline I B $(\mathbf{n = 1 1})$ & $0.125 \pm 0.125^{\mathrm{a}}$ & $0.125 \pm 0.125^{\mathrm{a}}$ & $\mathbf{1 . 1 2 5} \pm \mathbf{0 . 1 2 5 ^ { \mathrm { b } }}$ \\
\hline II A $(\mathbf{n = 8})$ & $0.273 \pm 0.141$ & $0.273 \pm 0.141$ & $\mathbf{0 . 5 4 5} \pm \mathbf{0 . 1 5 7 ^ { * }}$ \\
\hline II B (n=14) & $0.375 \pm 0.183$ & $0.375 \pm 0.183$ & $\mathbf{0 . 7 1 4} \pm \mathbf{0 . 1 8 4}$ \\
\hline
\end{tabular}

* Significantly $(\mathrm{P}<0.05)$ different between groups at same interval

Table.3 Observation on rumen motility and survivability in different groups of dystocia affected buffaloes

\begin{tabular}{|c|c|c|c|}
\hline \multirow[t]{2}{*}{ Group } & \multicolumn{3}{|c|}{ Sampling interval Rumen Motility } \\
\hline & 0 hour & 2 hours & 24 hours \\
\hline$S(n=24)$ & $0.333 \pm 0.098$ & $0.208 \pm 0.084$ & $0.875 \pm 0.091$ \\
\hline D $(n=17)$ & $0.352 \pm 0.119$ & $0.187 \pm 0.100$ & $0.133 \pm 0.090 * *$ \\
\hline$S I(n=13)$ & $0.230 \pm 0.121$ & $0.230 \pm 0.121$ & $0.923 \pm 0.136$ \\
\hline D I $(n=6)$ & $0.166 \pm 0.166$ & $0.166 \pm 0.166$ & $0.33 \pm 0.120 *$ \\
\hline S II $(n=11)$ & $0.454 \pm 0.157$ & $0.181 \pm 0.121$ & $0.818 \pm 0.121$ \\
\hline D II (n=11) & $0.454 \pm 0.157$ & $0.20 \pm 0.13$ & $0.0 \pm 0.0 * *$ \\
\hline S B $(n=12)$ & $0.333 \pm 0.142$ & $0.250 \pm 0.130$ & $0.750 \pm 0.130$ \\
\hline D B $(n=13)$ & $0.307 \pm 0.133$ & $0.083 \pm 0.083$ & $0.833 \pm 0.083$ \\
\hline
\end{tabular}

* Significantly $(\mathrm{P}<0.05)$ different between groups at same interval

** Significantly $(\mathrm{P}<0.01)$ different between groups at same interval

Ruminal motility was observed to be adversely affected by pre-emptive administration of meloxicam in dystocia affected buffaloes and caesarean operation further added to this effect on rumen function. Whether meloxicam administration has a deleterious effect on rumen movement is a subject of further detailed investigation as no report on effect of meloxicam on rumen function could be traced by the author in available literature. However, repeated meloxicam administration has been shown to 
have serious gastrointestinal disorder in dogs (Enberg et al., 2006). Rumen function has been reported to be adversely affected in buffaloes with dystocia (Atwal, 1993; Dahiya, 1998). The decreased ruminal motility may be due to stress of dystocia and associated anorexia. The buffaloes included in the present study had been anorectic for varying periods before the case was presented for treatment. Significant improvement was noticed in ruminal motility by 24 hours post treatment in buffaloes which survived when compared with the pre-treatment value and also in comparison to those which died after obstetrical management of dystocia. This is in agreement with the observations of Atwal (1993) in dystocia affected buffaloes. According to Rebhun (1987) and Franklyn (1990) the rumen function fails to improve in animals which are under severe stress and toxaemia.

\section{References}

Atwal, J.S. (1993). Studies on the stress of dystocia in buffaloes. M.V.Sc. Thesis, Punjab Agric. Univ. Ludhiana. India.
Dahiya, N.K. (1998). Studies on post caesarian rumen function and the use of b-adrenergic agonists in buffaloes with dystocia. M.V.Sc. Thesis Haryana Agric. Univ., Hisar, India.

Dukes, H. H. (1955). The physiology of domestic animals. Ithaca, N.Y. Comstock Publishing Assoc., $7^{\text {th }}$ Ed.1020.pp.

Enberg, T.B., Braun, L.D.a nd Kuzma, A.B. (2006). Gastrointestinal perforation in five dogs associate with the administration of meloxicam. Journal Veterinary Emergency and critical care.16: 34-43.

Franklyn, G. (1990). Managing forestomach problems caused by motor diseases. Vet. Med. 85 (6): 651-679.

Khan, H.M., Bhakat, M. and Mohanty, T.K. (2009). Peripartum reproductive disorders in buffaloes - an overview. Vet Scan,4:1-10.

Rebhun, W.C. (1987). Rumen collapse in cattle. Cornell Vet. 77: 244-250.

Schalk, A. F and Amadon, R. S. (1928). Physiology of ruminant stomach. N. Dakota Agr. Exp. Stat. Bull. Pp. 216.

\section{How to cite this article:}

Umed Singh Mehra, S.C. Arya, Praveen Kadian, Rajan Chaudhary, Ravi Dutt, Rajendra Yadav and Pankaj Kumar. 2018. Effect of Pre Emptive Administration of Meloxicam on Rumen Motility in Dystocia Affected Buffaloes. Int.J.Curr.Microbiol.App.Sci. 7(05): 1818-1823. doi: https://doi.org/10.20546/ijcmas.2018.705.214 